\title{
IMPACT RESPONSE OF AIRCRAFT STRUCTURES ENHANCED WITH CRUSHABLE ENERGY ABSORBERS: CRASHWORTHINESS ANALYSIS AND PASSENGER INJURY ASSESSMENT
}

\author{
JAVIER PAZ, JACOBO DÍAZ \& LUIS ROMERA \\ Universidade da Coruña - Structural Mechanics Group, School of Civil Engineering, Spain
}

\begin{abstract}
The following research studies and enhances the structures from a commercial aircraft fuselage section by implementing crushable energy absorbers as vertical struts. The previously-developed numerical simulation from the drop test of a Boeing 737-200 is used, both featuring and lacking the auxiliary fuel tank, with the latter offering a more harmful response. Five crushable absorbers were then added to the cargo compartment connecting the frames with the underfloor beams seeking the modification of the collapse mechanism of the aircraft and, consequently, a more progressive and safer behavior. The results obtained show a reduction of the acceleration peaks by over $50 \%$ when the absorbers are fitted in the section without a fuel tank. Moreover, the acceleration plots in the Eiband diagram also reveal a reduction of the passenger injury assessment from severe to moderate. An in-depth analysis of the energy values during the simulation shows an energy absorption of $25 \mathrm{~kJ}$ from the absorbers, as well as the increase of the plastic dissipation by the frames from $76 \mathrm{~kJ}$ to $104 \mathrm{~kJ}$.
\end{abstract}

Keywords: crashworthiness enhancement, Eiband diagram, crushable energy absorbers.

\section{INTRODUCTION}

Society's ever-growing concern with safety and efficiency has actively conditioned the transport industry and its progress since the 1960s. Significant advances have arisen from this trend, as the use of composite materials and metallic alloys for reduced structural weight, or the implementation of crashworthiness tests and standards as those from the Federal Aviation Administration (FAA) or the Joint Airworthiness Requirements (JAR) [1]. The crashworthiness of structures, measured by the quality of the response when the vehicle undergoes a crash, is increased the less the occupants and structures are damaged after the impact. In the particular case of aircraft structures, their crashworthiness performance may be improved by modifying the collapse process by which they are crushed, or increasing the energy absorption capabilities for impact attenuation. To assess this, real tests and numerical simulations are conducted as to obtain data on the accelerations and loads transmitted to the occupants, as well as determining the structural response.

Rather than studying the complete aircraft structural assembly, research has mainly deepened into specific areas including the sub-floor structures, the main frames, or the vertical struts which connect the under-floor beams and the sub-floor structures [2]. The addition of such enhancements lessens the severity of passenger injuries by increasing the energy dissipation during impact scenarios as hard-landing or water-ditching [3].

Vertical struts are used in some civil aircraft designs, as the Airbus A320 or the Fokker F28 [4], with the main purpose of providing vertical support for the cabin floor. However, following the idea of the "controlled load concept" from Kindervater et al. [5], several investigations have assessed the effect of struts as crashworthy elements [6]. Yiru et al. [7] determined that the strut's stiffness was a key factor for damping acceleration loads and maintaining a livable crush space. While stiff struts avoid excessive crushing of the subfloor area and reduce the risk of bottoming-out, they also transmit higher force peaks to the 
occupants; thus suggesting the need for a trade-off between the two desired responses [8]. The position and angle of the struts in the fuselage is also critical for occupant protection, as they influence the aforementioned plastic hinge location. By discretely modifying the insertion angles with the floor beams and the main frames, Ren and Xiang [9] concluded that best energy absorption and acceleration trends where obtained for oblique struts, although sacrificing cargo space.

Concerning the geometry and materials of the strut, several options have arisen. Ren and Xiang [10] analyzed the effect of including triggered quadrangular oblique struts in a generic civil aircraft, showing that optimum performance was achieved with aluminum thicknesses slightly under one millimeter for the struts. Heimbs and Middendorf [11] proved that composite struts forced to pass through a deflection and cutting device not only showed a robust and effective crushing, but they also are adjustable for different needs by modifying composite ply configurations, the design of shear pins or the number of cutting holes. As in the sub-cargo region, continuous sine-wave beams replacing vertical struts also offer an efficient solution for stable energy dissipation [12].

This investigation is focused on the development and improvement of novel energy absorption devices intended for its usage in aeronautical applications. For that, a numerical model from a Boeing 737-200 fuselage section, previously developed in Paz et al. [13] through reverse engineering techniques and verified with both static internal pressure tests and a hard-landing impact, is used as a benchmark in which the effect of struts can be analyzed. Two impact scenarios are considered, both with and without the auxiliary fuel tank, studying the collapse mechanisms and the crashworthiness performance of the structural configuration when colliding with solid ground. After five thin-walled square tubes are fitted on the cargo area as vertical struts and the crash scenarios are again analyzed, while the improvement induced by these structures is characterized according to aircraft efficiency and passenger biometric criteria.

\section{FUSELAGE MODEL DESCRIPTION}

The following research relies on the data from the experimental drop test of a Boeing 737200 fuselage section at the FAA William J. Hughes Technical Center (New Jersey, USA) in November of 2000 [14]. In the test, the $3.05 \mathrm{~m}$ long fuselage section was released from $4.27 \mathrm{~m}$ and dropped against a wooden block impacting it at $9.144 \mathrm{~m} / \mathrm{s}$, thus constituting a severe but survivable crash. As the section had been thoroughly instrumented, there exist plenty of acceleration and strain data at several locations through the fuselage which can be used to validate the numerical model. Moreover, these data can be used to construct Eiband diagrams [15] at the desired locations as to assess passenger injury predictions during the impact.

The original fuselage model was verified in Paz et al. [13] against the experimental results from Fasanella and Jackson [14], so it can be now used as a benchmark to study the performance of a fuselage section with vertical struts implemented. The struts added are composed by $700 \mathrm{~mm}$-long aluminum tubes with a square cross-section width of $80 \mathrm{~mm}$ and wall thicknesses of 2.5 and $1.2 \mathrm{~mm}$ for the top and bottom halves, respectively. This dimensions ensure its progressive collapse according to Abramowicz and Jones [16] for axially-dominated loading, as the minimum critical length for the tube is $L_{\mathrm{cr}}=984 \mathrm{~mm}$. While the thinner region is designed to collapse first and trigger a stabilized folding mechanism, the thicker plates allow for higher energy absorption values in case it were required. Seeking the highest inertia in the transverse direction of the fuselage as to minimize off-plane buckling, the struts are rotated along the vertical axis $45^{\circ}$. The struts are connected with pinned joints, allowing the rotation along the transverse plane, giving 
structural continuity to the main frames and cabin floor beams. Moreover, they are spaced $2.04 \mathrm{~m}$ apart along the transverse direction to maintain the clearance required for the auxiliary fuel tank and the standardized cargo containers [17]. In the longitudinal axis, the absorbers are spaced every meter when if attachment is feasible. For this section, the cargo door impedes the insertion of a vertical strut in the affected frame, leading to a section with a total of five absorbers.

\subsection{Materials}

Three material definitions are required for the simulations of the fuselage section studied. The AA2024-T3 aluminum [18] alloy is used for the fuselage skin and floor section, while the AA7075-T6 aluminum [19] is used for the airframe: under-floor beams, stringers, and frames. The AA7075-T6 alloy is also used for the vertical struts, since it exhibits higher stiffness than the AA2024-T3 aluminum, consequently increasing the triggering load and limiting plastic deformation during normal flight conditions. Both aluminums are modeled with the Johnson-Cook strain-rate sensitive plasticity models [20] without temperature effects. Moreover, considering that the fuselage section had been obtained from an used aircraft [14], the elastic and plastic parameters from the material model are reduced by $20 \%$ following the recommendation from Fasanella and Jackson [21] to account for fatigue effects. The values used for the Johnson-Cook plasticity models implemented are detailed in Table 1.

Table 1: Material properties of the AA2024-T3 and AA7075-T6 aluminum alloys, the tank material [14] and the impacting block.

\begin{tabular}{llrrrr}
\hline \multicolumn{2}{c}{ Parameter } & AA2024-T3 & AA7075-T6 & Tank & Wood \\
\hline \multirow{2}{*}{ General } & $\mathrm{E}(\mathrm{GPa})$ & 73.08 & 72.4 & 72.4 & 0.5 \\
properties & $\nu$ & 0.33 & 0.33 & 0.3 & 0.3 \\
& $\rho\left(\mathrm{kN} / \mathrm{m}^{3}\right)$ & 2.78 & 2.78 & 4.94 & 1.2 \\
\hline \multirow{4}{*}{ Plasticity } & $\mathrm{A}(\mathrm{MPa})$ & 302 & 413 & 682.6 & - \\
model & $\mathrm{B}(\mathrm{MPa})$ & 550 & 600 & - & - \\
& $\mathrm{C}$ & 0.73 & 0.71 & - & - \\
& $\mathrm{\varepsilon}$ & $3 \mathrm{e}-4$ & $1 \mathrm{e}-4$ & - & - \\
\hline
\end{tabular}

\subsection{Numerical simulation}

The Abaqus CAE software in its 2016 version was used for the numerical representation and simulation of the fuselage section. The numerical model contains all the representative features from the real test article, including the skin stiffeners, the cargo door and its stiffening beams, the mass of seats and passengers, and the filled auxiliary fuel tank. The experimental article accounted for 12 accelerometers as to record data from the test, with the location of two being chosen as acceleration extraction points for the verification of the simulation, shown in Fig. 1 as locations 1 and 2. Location 1 represents the data extraction point on the left side of the station FS420 and 2 the point on the right; both measured at the seat tracks on the fuselage floor. The data points $1 \mathrm{~b}$ and $2 \mathrm{~b}$ are vertically aligned with the location of an energy absorber as to retrieve the resulting acceleration profiles to guarantee that the implementation of struts does not lead to high acceleration peak values. Furthermore, a connector was developed for 
the model with vertical struts, providing a linkage between absorber and frame. These parts were designed with the same aluminum alloy and are rigidly connected to the tubes.

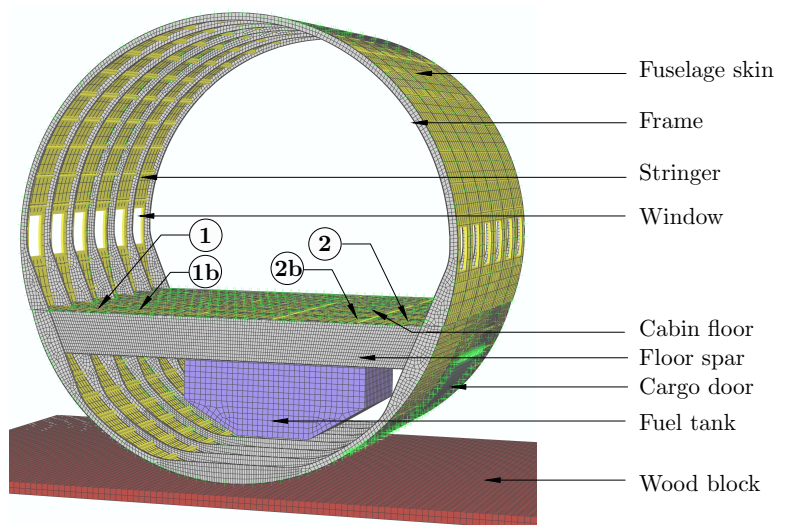

Figure 1: Numerical model in Abaqus 2016.

The selection of the mesh size and element type is performed according to characteristics and expected behavior of each structure. Thus, the skin, frames, floor, beams, and tank panels are modeled with shell elements with four nodes and reduced integration (S4R), while stringers are represented with 2-node linear beam elements (B31). This reduces the computational cost of the simulation with little effect on the final results. To represent the passenger and seats, an array of distributed masses is added to the cabin floor. Finally, solid elements with eight nodes and reduced integration (C3D8R) are used to mesh the impact surface.

The numerical model also includes the windows and window frames from the original fuselage, although the corners have been simplified as right angles to avoid small and distorted elements around chamfers. More measures were adopted to further reduce computational costs, excluding complex features and geometry as joints, doubles, or cutouts. The auxiliary fuel tank from the test article is also included in the simulation, connecting it to the floor beams and representing the 404 gallons of water used in the experiment through evenly-distributed point inertias within the tank. It is important to note that this simplification of the fluid neglects any sloshing effect observed in the experiment.

The mesh of the numerical model was approached seeking the best compromise between accuracy and computational cost. The fuselage model is composed by 77,289 nodes and 65,391 elements, although with the addition of the finely-meshed vertical struts and connectors, the number of elements increases to a total of 94,496. An image of the fuselage section's mesh is also shown in Fig. 1. Concerning the total mass of the models, there is a slight discordance between the experimental article from [14] and numerical model here developed, weighing $3980 \mathrm{~kg}$ and $3890 \mathrm{~kg}$ respectively. The addition of the vertical struts and connectors accounts for a fuselage mass increase of $11.07 \mathrm{~kg}(0.3 \%)$, corresponding to 1.14 per strut and $1.07 \mathrm{~kg}$ from each connector.

\subsection{Analysis settings}

To match the impact conditions of the original experiment, an impact velocity of $9.144 \mathrm{~m} / \mathrm{s}$ was selected. To further characterize the behavior of the craft, the verified model is again 
analyzed without the auxiliary fuel tank in the cargo compartment, as the collapse mechanism of the fuselage is significantly influenced by this feature [22]. Both scenarios are finally repeated with the addition of the crushable vertical struts as to understand their effect on the global aircraft crash mechanics.

The difference in mesh sizes between the main fuselage structures and the thin-walled absorbers calls for the usage of subcycling techniques, which allows for different time increments for individual sets of nodes within a model. An element set was created with the energy absorbers and it was later subcycled, as its time increment was over ten times smaller than the non-subcycled model, yielding time gains of over ten hours for the original 37-hour fuselage drop test simulation.

\section{RESULTS}

\subsection{Fuselage without energy absorbers}

\subsubsection{Fuselage with auxiliary fuel tank}

The response from the original fuselage section is analyzed according to biometric criteria with the data extracted from the two representative locations in Fig. 1. The velocity and acceleration responses were also monitored for both sides of the fuselage floor. The graphs in Fig. 2 show the comparison for the two data extraction locations between the acceleration trends filtered with a 48-Hz four-pole Butterworth low-pass filter forwards and backwards as performed by Fasanella and Jackson [14]. Both graphs show a significant resemblance with the experimental results, matching the velocity slope changes and the peak acceleration values throughout the entire simulation and with differences in peak values under $15 \%$.

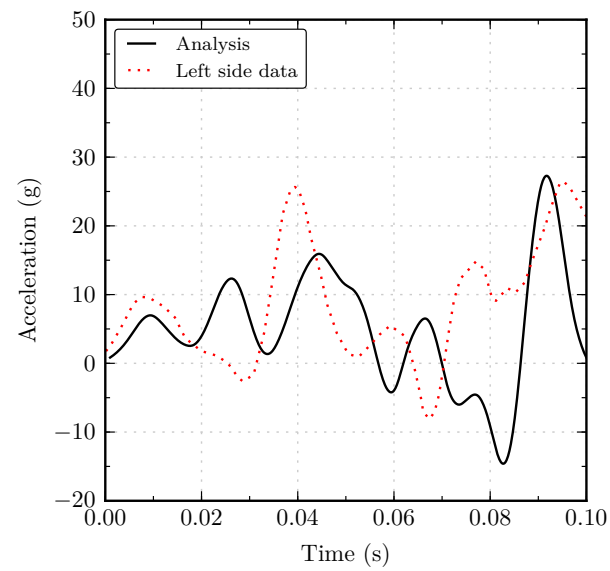

(a) Left floor acceleration (location 1).

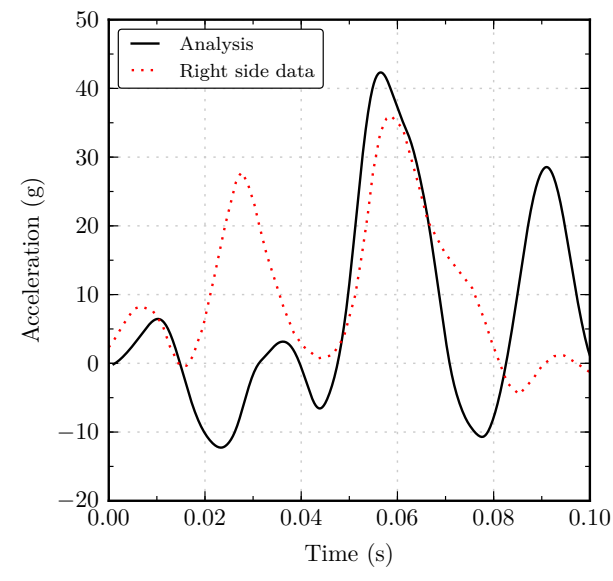

(b) Right floor acceleration (location 2).

Figure 2: Left and right floor accelerations. Experimental and numerical results.

The energy values and ratios were also checked throughout the analysis as to determine the stability and convergence of the simulation. In this analysis, the artificial-to-internal energy ratio is kept under $9 \%$ all through the simulation, which fall under the maximum recommended value of $10-15 \%$ in such non-linear dynamic numerical analyses. The adjustment between the experimental and numerical responses was also compared against 
the validation performed by Fasanella and Jackson [14], which delivered a similar adjustment between the experimental and simulation accelerations as those here obtained.

\subsubsection{Fuselage without auxiliary fuel tank}

A closer examination of the results from the unmodified fuselage reveals that the auxiliary fuel tanks dissipates over $55 \mathrm{~kJ}$ of kinetic energy through plastic deformation. Thus, the component is removed and analyzed again to see the effect of not featuring the tank. Moreover, it was found that unlike in the original analysis, where 100 milliseconds were enough to capture the whole collapse process, the simulation without the fuel tank requires an analysis of 150 milliseconds to capture the deformations in the latest parts of the process. When there is no auxiliary tank, the deformation in the lower part of the frames is increased, increasing maximum deformation values from $52.7 \mathrm{~cm}$ to $69.8 \mathrm{~cm}$ on the left side and by over $17 \mathrm{~cm}$ on the right. This augmented deformation leads to the undesirable impact of the lowest sub-floor structures with the floor beams, consequently affecting the peak acceleration values on the latest part of the simulation.

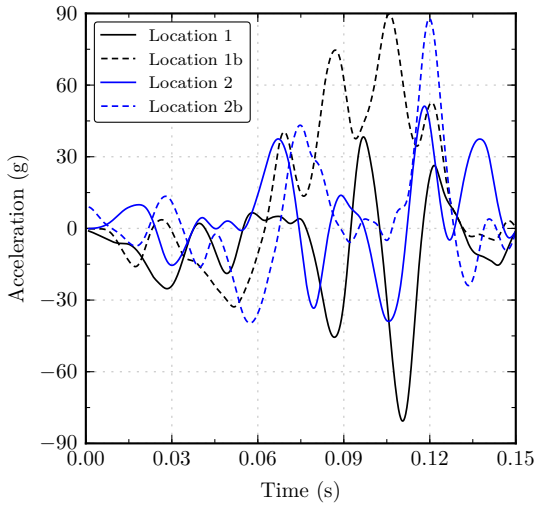

(a) Vertical accelerations at measured locations.

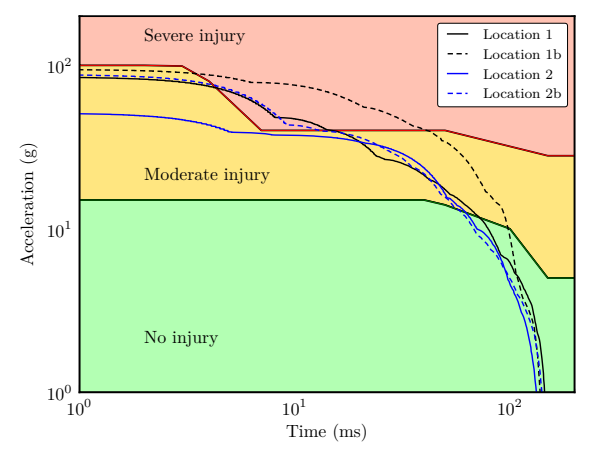

(b) Eiband diagram for vertical accelerations at measured location.

Figure 3: Vertical accelerations and depiction in Eiband diagram for fuselage without the auxiliary fuel tank and without energy absorbers.

Vertical accelerations are retrieved at the aforementioned locations an presented in Fig. 3(a), where the collision between frames and floor beams becomes apparent with the high acceleration peaks neighboring 90 g's observed approximately $100 \mathrm{~ms}$ into the simulation, surpassing the recommended limits leading to passenger injury [23]. This is complemented with the Eiband diagram from Fig. 3(b), offering a depiction of the vertical accelerations at the floor level, although the loads experienced by passengers at those locations in a real event would be lower due to factors as the usage of seat restraints and cushion damping. With the exception of location 2, where acceleration profile falls within the moderate injury region, all others are well into the severe injury region, with location $1 \mathrm{~b}$ being the most harmful of them.

A closer examination of the post-test fuselage from Fig. 7(b) shows the significant deformation on the sub-floor region, while the frames only dissipate a limited amount of energy localized at local plastic hinges. Consequently, the aircraft's crash stroke is rapidly exhausted, leading to impact of the lower part of the frames with the passenger floor. This 
effect not only increases acceleration peaks at the occupant locations, but can also lead to higher injury risk by environmental factors.

\subsection{Effect of the energy absorbers}

Once the crashworthiness performance of the model is verified, the vertical struts are added and the data obtained is compared to that from the original fuselage section. The vertical struts are tested for a fuselage section with the auxiliary fuel tank and for another section without it.

In order to assess the improvement obtained from the usage of the energy absorbers, the Eiband diagram is used together with the acceleration responses for two locations on the left side of the fuselage, 1 and $1 \mathrm{~b}$ (see Fig. 1), and the two symmetrically opposed on the right side, 2 and $2 b$.

\subsubsection{Fuselage with auxiliary fuel tank}

The effect of struts on the acceleration response for the fuselage sections with the auxiliary fuel tank was analyzed and depicted in Fig. 4. Results show a similar trend on location 1, but with slightly higher acceleration values for the model with the energy absorbers throughout most of the simulation. However, on location $1 \mathrm{~b}$ the responses differ significantly between both scenarios, even though the acceleration peaks are almost identical.

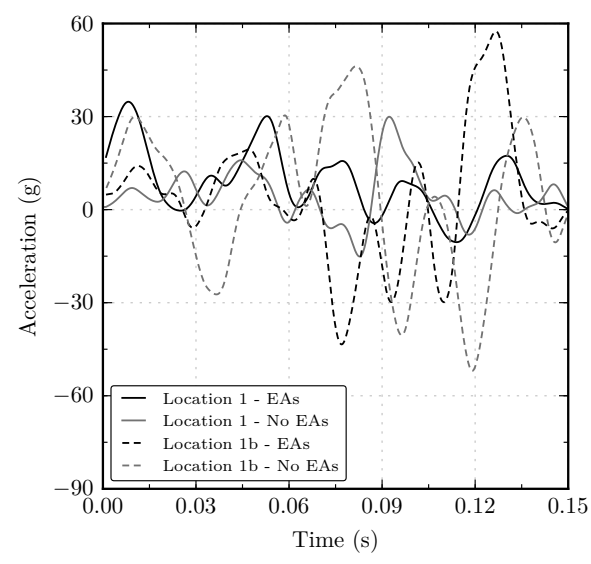

(a) Accelerations at locations 1 and $1 \mathrm{~b}$.

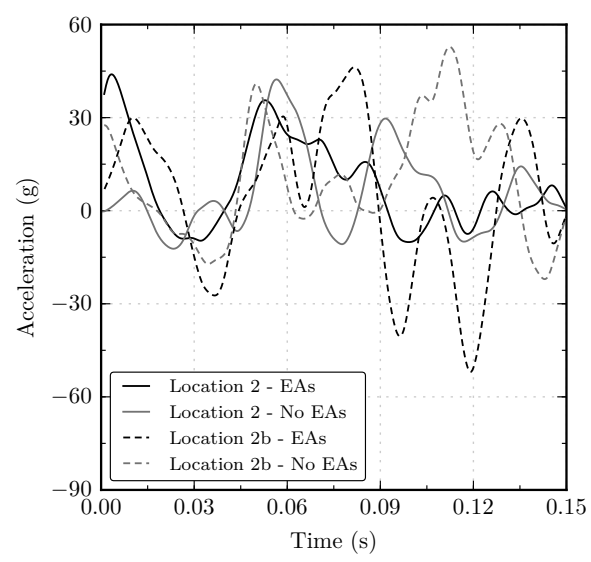

(b) Accelerations at locations 2 and 2 b.

Figure 4: Aircraft acceleration responses with the auxiliary fuel tank, with and without energy absorbers.

The Eiband diagram in Fig. 5 is used to compare the plausible injuries at the locations monitored. After implementing the energy absorbers to the model, the injury rating is lowered on location 1 , even though the outcome for location $1 \mathrm{~b}$ is slightly more harmful. Moreover, Figs 6(a) and 6(b) help in further understanding the crush evolution of the strut under location 1b. In the force-displacement graph from Fig. 6(b) an initial crushing peak force of $40 \mathrm{kN}$ is required to initiate the strut's collapse, while the crushing force after this peak is maintained within the 20-30 kN range. In the end, after approximately $90 \mathrm{~ms}$ since the start of the fuselage impact, the energy absorber ceases to absorb and dissipate energy as the fuselage's cargo compartment stops collapsing. 


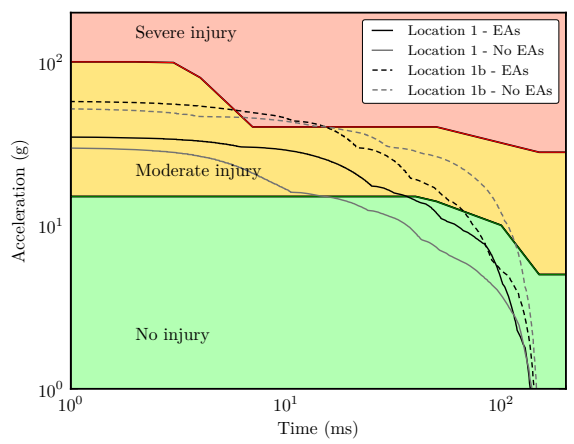

(a) Vertical acceleration loads at locations 1 and $1 b$.

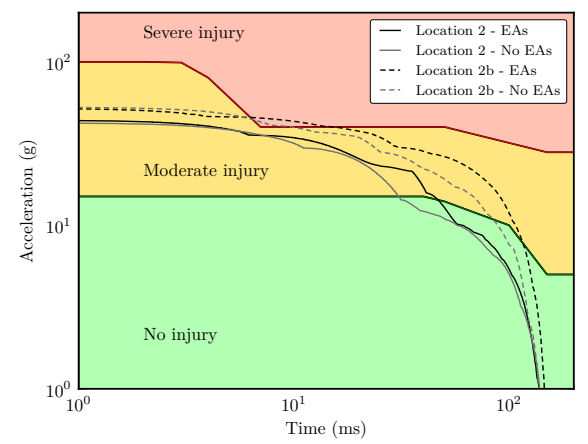

(b) Vertical acceleration loads at locations 2 and $2 b$.

Figure 5: Vertical acceleration loads in Eiband diagram. Fuselage with the auxiliary fuel tank, with and without energy absorbers.

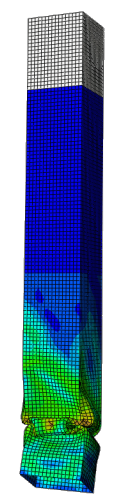

(a) Final deformation of strut under location $1 b$.

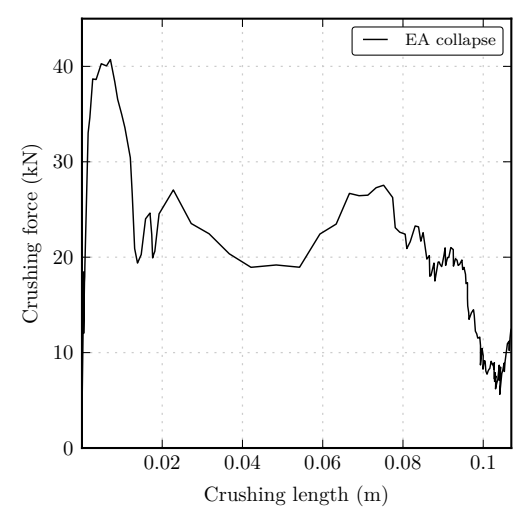

(b) Response of strut under location $1 b$.

Figure 6: Vertical strut after impact and response.

\subsubsection{Fuselage without auxiliary fuel tank}

In the event of a hard-landing scenario without the auxiliary fuel tank, the contribution of the energy absorbers is even more significant than in the previous case. A closer examination to the collapse evolution of the main structures reveals how the collision with the ground crushes the sub-cargo area after $20 \mathrm{~ms}$. Another $20 \mathrm{~ms}$ into the simulation, the main frames experience high localized deformation at the struts' insertion areas, forming two plastic hinges on each frame that allow for a flattening of this region. Although the lower part of the struts undergoes some deformation before this point, it is only after 50-60 ms that absorbers fully collapse under post-buckling conditions, developing between one or two folds. Finally, after $80 \mathrm{~ms}$ the floor spars bend near the middle section while struts crushing continues until the specimen completely comes to a halt. 


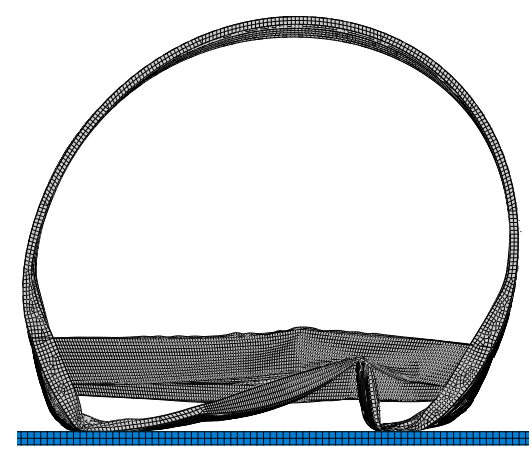

(a) Final deformation of the specimen without energy absorbers.

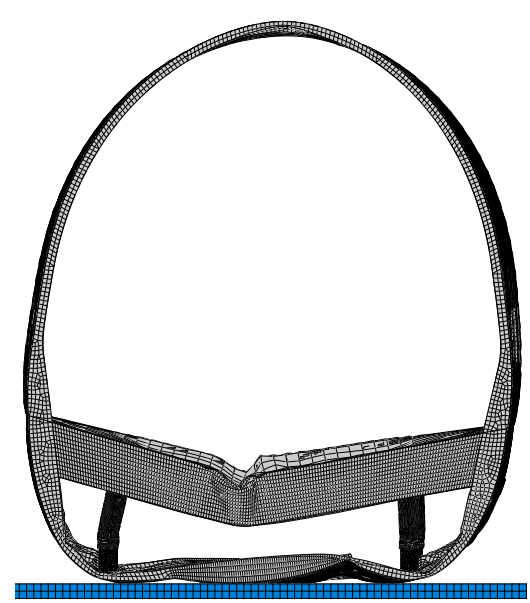

(b) Final deformation of the specimen with energy absorbers.

Figure 7: Final deformation of the specimen without the auxiliary fuel tank, without and with energy absorbers.

Figure 7 offers the post-test final deformation for two fuselage sections without the auxiliary fuel tank. When comparing Fig. 7(a) and Fig. 7(b), it is clear that the absence of a fuel tank results in a higher deformation of the sub-cargo area. However, the vertical struts not only ensure a higher sub-cargo area after the impact, but they also delay the bottom-out effect observed in Fig. 7(a), and therefore, lower acceleration loads are transmitted to the passengers in the final $50 \mathrm{~ms}$ of the crushing process (Fig. 3(a)). The location where the plastic hinges form in the main frames is also affected, as bending occurs where the struts are inserted rather than on the outer regions of the frame. Consequently, the frames' plastic dissipation capabilities are better exploited, increasing this value from the original $76 \mathrm{~kJ}$ to $104 \mathrm{~kJ}$.

The acceleration graphs from Fig. 8 compare the acceleration felt at locations 1 and $1 \mathrm{~b}$ both with and without energy absorbers. The earliest 50-60 ms show that the fuselage with the energy absorbers undergoes higher acceleration loads than the original configuration. This is caused by the presence of the struts, which initiate the collapse for high triggering loads to ensure a correct behavior during the normal flight operation conditions.

As the crushing continues, the original specimen bottoms-out and the lowest section of the frames hits the underfloor beams, resulting in acceleration peaks of over $90 \mathrm{~g}$ 's. However, since the section with the energy absorbers experiences a more controlled collapse and the energy absorbers dissipate up to $6 \%$ of the fuselage's kinetic energy through plastic deformation, the acceleration peaks at less than $45 \mathrm{~g}$ 's, $50 \%$ less than in the original specimen.

Moreover, the contribution offered by the energy absorbers is ever best perceived in the Eiband diagram from Fig. 9. In the scenario with no vertical struts, the acceleration loads experienced on both locations can lead to severe injuries, mainly caused during the latest stages of the impact. However, in the enhanced section, the injuries are on the moderate injury region due to the more stable collapse mechanism obtained and the energy dissipated by the energy absorbers. 


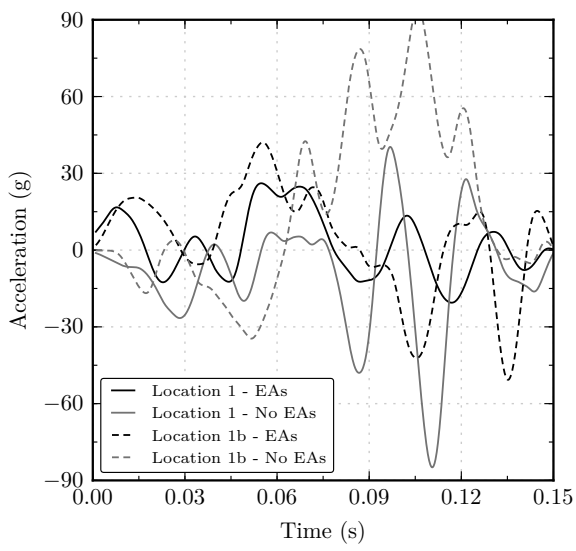

(a) Accelerations at locations 1 and $1 \mathrm{~b}$.

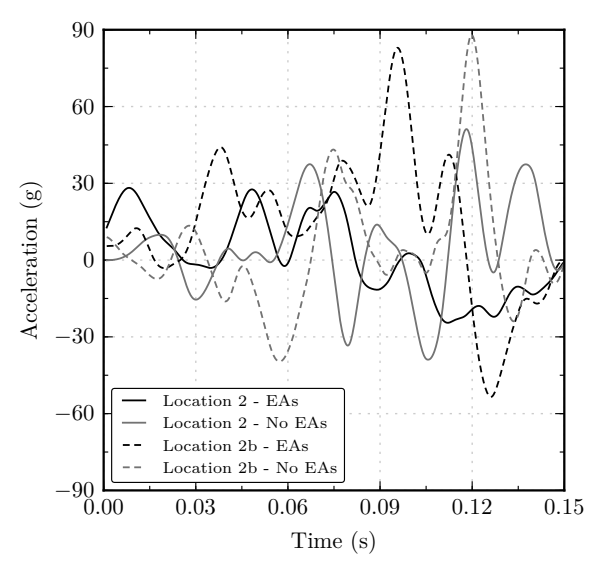

(b) Accelerations at locations 2 and $2 \mathrm{~b}$.

Figure 8: Aircraft acceleration responses without the auxiliary fuel tank, with and without energy absorbers.

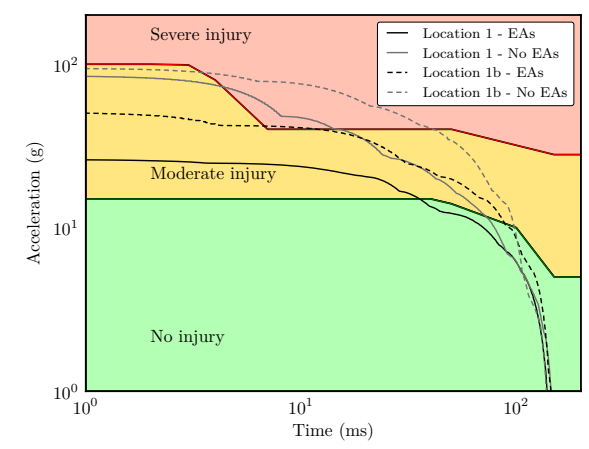

(a) Vertical acceleration loads at locations 1 and $1 \mathrm{~b}$.

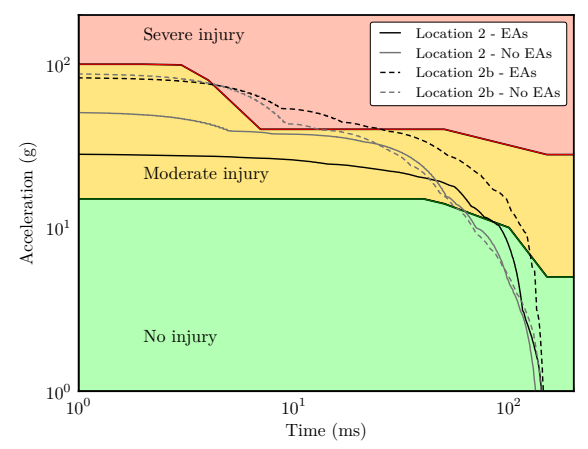

(b) Vertical acceleration loads at locations 2 and $2 b$.

Figure 9: Vertical acceleration loads in Eiband diagram. Fuselage without the auxiliary fuel tank, with and without energy absorbers.

\section{CONCLUSIONS}

For this research, crushable metallic energy absorbers are developed and studied under axial impact loads on aircraft structures using a validated numerical impact simulation of a 10-foot long fuselage section from a Boeing 737-200. Crashworthiness metrics are evaluated before and after the implementation of the energy absorbers to determine their overall effect on the aircraft. The following conclusions are drawn:

- Eiband diagrams determine that injury ratings on the occupants are more harmful in the scenario without the auxiliary fuel tank, as the acceleration loads are well in the "severe injury" region with acceleration peaks of over $90 \mathrm{~g}$.

- The addition of crushable energy absorbers enhances the crashworthiness performance of the aircraft. For the model with the fuel tank, peak acceleration is lowered by $25 \%$ 
at the original measuring location, without noticeable detriment of the response over the vertical strut's location.

- In the event of an impact without the auxiliary fuel tank, the usage of the square energy absorbers reduces the peak acceleration by up to $50 \%$ and provides a softer acceleration profile. The enhancement stems from the energy absorption provided by the struts as well as the plastic dissipation of the frames, increased from $76 \mathrm{~kJ}$ to 104 $\mathrm{kJ}$ as the absorbers modify the original structural collapse mechanism of the fuselage. Furthermore, the usage of crushable struts lowers the injury criteria from severe to moderate on both locations and ensures a bigger survivable space in the under-floor compartment.

- The addition of square crushable energy absorbers does not significantly affect the crashworthiness performance of the aircraft for the model with the fuel tank. Peak acceleration is slightly increased at two of the measuring locations, while it is kept at a similar value at the others.

\section{ACKNOWLEDGEMENTS}

The research leading to these results has received funding from the Spanish Government (Ministerio de Economía y Competitividad) under grant agreement DPI2016-76934-R. The authors fully acknowledge the support received.

\section{REFERENCES}

[1] De Florio, F., Airworthiness: An Introduction to Aircraft Certification, Oxford, 2006.

[2] Heimbs, S., Energy absorption in aircraft structures. International Workshop on Hydraulic Equipment and Support Systems for Mining, 2012.

[3] McCarthy, M., Harte, C., Wiggenraad, J., Michielsen, A., Kohlgrueber, D. \& Kamoulakos, A., Finite element modelling of crash response of composite aerospace sub-floor structures. Computational Mechanics, 26(3), pp. 250-258, 2000.

[4] Lyle, K.H., Stockwell, A.E. \& Hardy, R.C., Application of probability methods to assess airframe crash modeling uncertainty. Journal of Aircraft, 44(5), pp. 1568-1573, 2007.

[5] Kindervater, C., Kohlgruber, D. \& Johnson, A., Composite vehicle structural crashworthiness-a status of design methodology and numerical simulation techniques. International Journal of Crashworthiness, 4(2), pp. 213-230, 1999.

[6] Kumakura, I., Minegishi, M., Iwasaki, K. \& Hosokawa, T., Impact simulation of simplified structural models of aircraft fuselage. SAE transactions, 109(1), pp. 12381243, 2000.

[7] Yiru, R., Jinwu, X., Zhangping, L. \& Jianqiang, Z., Effect of cabin-floor oblique strut on crashworthiness of typical civil aircraft fuselage section. Acta Aeronautica Et Astronautica Sinica, 2, p. 012, 2010.

[8] Kumakura, I., Minegishi, M. \& Iwasaki, K., Impact simulation of simplified structural models of aircraft fuselage. 2000 World Aviation Conference, 2000.

[9] Ren, Y. \& Xiang, J., A comparative study of the crashworthiness of civil aircraft with different strut configurations. International Journal of Crashworthiness, 15(3), pp. 321330, 2010.

[10] Ren, Y. \& Xiang, J., The crashworthiness of civil aircraft using different quadrangular tubes as cabin-floor struts. International Journal of Crashworthiness, 16(3), pp. 253262, 2011.

[11] Heimbs, S. \& Middendorf, P., Design, analysis and testing of a composite crash absorber for aeronautic applications. 3rd ECCOMAS Thematic Conference on the Mechanical Response of Composites, pp. 537-544, 2011. 
[12] Perez Galan, J.L., Climent, H. \& Le Page, F., Non-linear response of metallic and composite aeronautical fuselage structures under crash loads and comparison with full scale test. European Congress on Computational Methods in Applied Sciences and Engineering, ECCOMAS, Barcelona, 2000.

[13] Paz, J., Díaz, J. \& Romera, L., Crashworthiness study on hybrid energy absorbers as vertical struts in civil aircraft fuselage designs. International Journal of Crashworthiness, 25(4), pp. 430-446, 2020.

[14] Fasanella, E.L. \& Jackson, K.E., Crash simulation of vertical drop tests of two Boeing 737 fuselage sections. U.S. Army Research Laboratory, Vehicle Technology Center, Langley Research Center, 2002.

[15] Eiband, A.M., Human tolerance to rapidly applied accelerations: a summary of the literature. National Aeronautics and Space Administration (NASA), 1959.

[16] Abramowicz, W. \& Jones, N., Transition from initial global bending to progressive buckling of tubes loaded statically and dynamically. International Journal of Impact Engineering, 19(5-6), pp. 415-437, 1997.

[17] Airplanes, B.C., 737 Airplane Characteristics for Airport Planning. D6-58325-6, 2013.

[18] Kay, G., Failure modeling of titanium 6AI-4V and aluminum 2024-T3 with the Johnson-Cook material model. Office of Aviation Research, Federal Aviation Administration, 2003.

[19] Brar, N., Joshi, V. \& Harris, B., Constitutive model constants for al7075-t651 and al7075-t6. Shock Compression of Condensed Matter 2009: Proceedings of the American Physical Society Topical Group on Shock Compression of Condensed Matter, vol. 1195, AIP Publishing, pp. 945-948, 2009.

[20] Cook, G.R. \& Johnson, W.H., A constitutive model and data for metals subjected to large strains, high strain rates and high temperatures. Proceedings of Seventh International Symposium on Ballistics, 1983.

[21] Fasanella, E. \& Jackson, K., Best practices for crash modeling and simulation, 2002.

[22] Adams, A. \& Lankarani, H., A modern aerospace modeling approach for evaluation of aircraft fuselage crashworthiness. International Journal of Crashworthiness, 8(4), pp. 401-413, 2003.

[23] Desjardins, S., Zimmerman, R., Bolukbasi, A. \& Merritt, N., Aircraft crash survival design guide. US Army Aviation Systems Command TR, 89, 1989. 